\title{
Effect of mechanically induced micro deformations on extensibility and strength of individual softwood pulp fibers and sheets
}

\author{
Jarmo Kouko ( Marina Jajcinovic • Wolfgang Fischer • Annika Ketola • \\ Ulrich Hirn • Elias Retulainen
}

Received: 12 July 2018/Accepted: 26 November 2018/Published online: 4 December 2018

(C) The Author(s) 2018

\begin{abstract}
Tensile tests of individual bleached kraft pulp fibers and paper sheets of industrial origin were conducted in order to investigate the effect of refining and small-scale fiber deformations on the extensibility of fibers and paper. The shape of the tensile curves of most of the fibers was concave upward (i.e., increasing slope) and consisted of two or three phases suggesting that the fibrillar structure and disordered regions in the fiber wall were straightened out during straining. Only a few of the individual BSKP fiber tensile curves were apparently linear. Elongation of the individual kraft fibers varied from 8 to $32 \%$ and the average elongation
\end{abstract}

was not increased by high consistency refining. Tensile test results of laboratory sheets made of the same BSKP pulp suggested that the fiber bonding not only governs paper strength, but also is highly relevant for the elongation of fiber networks. The key conclusion related to this investigation and freely dried sheets was that the increased network elongation and strength after refining is mainly due to increased inter-fiber bonding and a higher shrinkage tendency of the fiber network and not due to the increased elongation or strength of individual fibers.
Electronic supplementary material The online version of this article (https://doi.org/10.1007/s10570-018-2163-y) contains supplementary material, which is available to authorized users.

J. Kouko $(\bowtie) \cdot$ A. Ketola $\cdot$ E. Retulainen

VTT Technical Research Centre of Finland Ltd,

Koivurannantie 1, 40400 Jyväskylä, Finland

e-mail: jarmo.kouko@vtt.fi

M. Jajcinovic · W. Fischer - U. Hirn Institut für Papier-, Zellstoff- und Fasertechnik, Graz University of Technology, Inffeldgasse 23, $8010 \mathrm{Graz}$, Austria

M. Jajcinovic · W. Fischer · U. Hirn

CD Laboratory for Fiber Swelling and Paper Performance, Inffeldgasse 23, $8010 \mathrm{Graz}$, Austria 


\section{Graphical abstract}

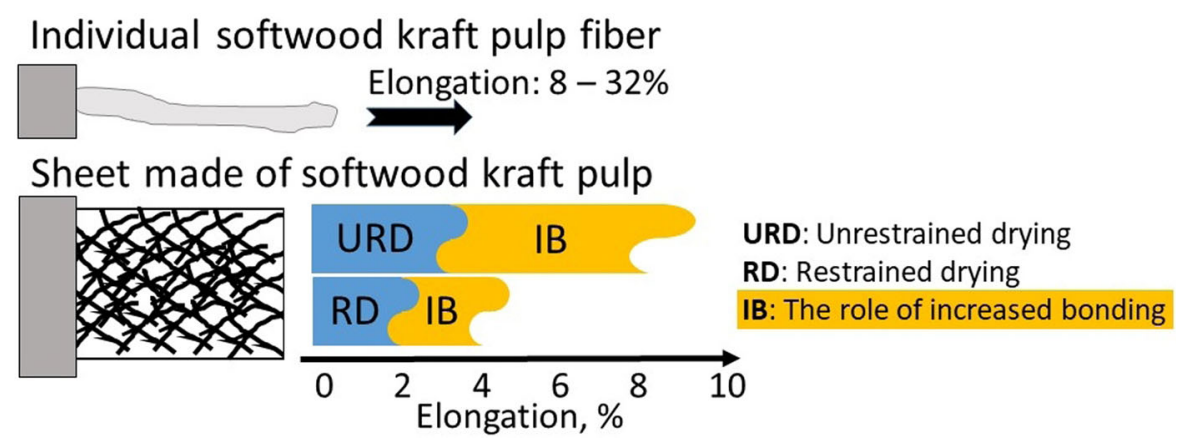

Keywords Individual softwood pulp fiber - Single fiber elongation - Stress-strain curve $\cdot$ Tensile testing . Viscose fiber

\section{Introduction}

Properties of individual pulp fibers play a pivotal role in the development of the mechanical properties of fiber networks and structures. Fiber strength determines the ultimate strength of paper and composite materials. However, the elongation potential of fiber networks is governed by the behavior of single fibers, inter-fiber bonding (Seth 2005) and the network properties (Vishtal and Retulainen 2014). Strength and extensibility of single fibers and the papermaking potential of fiber networks have been reviewed by Seth (2005), Lindström et al. (2005), and recently Vishtal and Retulainen (2014) and Hubbe (2014). High extensibility is a key material property for several paper packaging applications, e.g., paper sacks, paper cups or food trays. In this work, the effect of mechanical treatments on the load-elongation behavior of commercial bleached softwood kraft pulp (BSKP) fibers and the corresponding papers was studied in order to improve the extensibility of this type of materials.

Due to the small length and width $(0.7-3 \mathrm{~mm}$ length, 15-50 $\mu \mathrm{m}$ width) handling, mounting, and mechanical testing of individual pulp fibers is complicated and laborious. Another major difficulty regarding quantitative analysis is the natural variability of wood fibers caused by variation between trees. Furthermore there is variation related to location in the stem: early- and latewood (i.e., spring- and summerwood), compression wood (in softwoods), tension wood (in hardwoods), and variability in relation to radial and height position in a wood log (Groom et al. 2002; Lundqvist 2002; Gierlinger and Wimmer 2004; Luostarinen 2012). Additionally, pulp fibers are damaged, twisted or fibrillated in during chipping, pulping, and bleaching operations (Mott et al. 1995; Mohlin et al. 1996). In order to obtain reliable statistics for the pulp fiber properties, a sufficient number of fibers have to be tested.

There are several studies on the tensile properties of pulp fibers (Leopold and McIntosh 1961; Jentzen 1964; Spiegelberg 1966; Hill 1967; Alexander et al. 1968; Hardacker and Brezinski 1973; Duncker and Nordman 1965; Page et al. 1972; Page and Seth 1980; Page and El-Hosseiny 1983; Groom et al. 2002; Jajcinovic et al. 2016). Typically, tensile strength and also elastic modulus are reported but strain at break is often disregarded. When stress-strain curves of individual restrained dried fibers are presented (Jayme 1959; Kallmes and Perez 1965a, b; Van den Akker et al. 1965; Duncker and Nordman 1965; Leopold 1966; Hardacker and Brezinski 1973; Groom et al. 2002; Mott et al. 2002), they are typically practically linear or slightly concave downward, with an elongation to break of about 2-6\%. Significantly higher elongation values $(\sim 20 \%)$ have been reported for Longleaf pine fibers cooked in laboratory conditions and dried under longitudinal compression (Dumbleton 1971), for commercial Southern pine kraft pulp fibers dried individually on a Teflon treated glass plate allowing drying shrinkage (Hardacker and Brezinski 1973), and for Loblolly pine fibers selected from the 5 th annual ring at a low height of the tree (Groom et al. 2002; Mott et al. 2002). 
Microfibril angle (MFA) of the $S_{2}$ cell wall layer has been proven to be one of the most important factors influencing the mechanical properties of wood and pulp fibers (Page et al. 1972; Page and ElHosseiny 1983; Paavilainen 1993; Seth 2005; Long and Batchelor 2018). Page et al. $(1972,1977)$ used the mercury reflection technique in combination with a stereo-microscope for determining the fibril angle (MFA). Groom et al. (2002) used a confocal scanning laser microscope (CSLM) to determine the MFA of fiber specimens. Keunecke et al. (2008) used smallangle X-ray scattering and Wang et al. (2011) used an X-ray diffractometer to determine the MFA. Recently, Long and Batchelor (2018) measured bulk fibril angle using X-ray diffraction and the MFA of individual fibers using a confocal microscope and an analyzer crossed with polarization of the incident laser light. Fibers with a high MFA are more extensible than those with a low MFA, although variation at the same MFA can still be large (Page et al. 1972; Page and ElHosseiny 1983; Borodulina et al. 2015; Long and Batchelor 2018). Thin-walled earlywood fibers are weaker and less stiff compared to thick-walled latewood fibers. Thin-walled earlywood Scots pine fibers have a higher MFA compared to thick-walled latewood Scots pine fibers, whereas in Norway spruce the opposite has been observed (Lichtenegger et al. 1999). Drying under axial tension has been shown to decrease the MFA, i.e. increase the strength and reduce elongation (Jentzen 1964). Recently, also mechanosorptive creep rate has been measured and reported to correlate with the fibril angle (Dong et al. 2010; Olsson and Salmén 2014). Additionally, when fibril angles approach $45^{\circ}$ the wood fibers do not exhibit mechano-sorptive creep due to the low degree of anisotropy of the elastic and swelling properties of such high fibril angle fibers.

Mechanical treatment of pulp has been shown to be an efficient way to improve the elongation of paper. Three mechanisms are responsible for this. Firstly, improving the strength of the fiber-fiber bonding also increases the extensibility and strength of the paper. Poorly bonded fiber networks fail before the full elongation potential of fibers is reached, whereas in well-bonded networks the fibers are under higher stress and are more strained before network failure. Strong arguments have been presented that the nonlinearity and the viscoelastic properties of paper originate from within the fiber wall (Ebeling 1976;
Page and Seth 1980). Secondly, the creation of dislocations and microcompressions of fibers introduced by refining (Dumbleton 1971; Hamad et al. 2012) has also been identified as a cause for increased paper elongation. The mechanism assumed here is that these deformations are, at least partly, pulled straight during loading of the network, which increases paper elongation under load. Small fiber deformations (microcompressions and dislocations) thus lead to a higher elongation before a break of the individual fibers. Hamad et al. (2012) estimated the changes in microcompressions during single fiber tensile testing by using Raman microscopy. According to Hornatowska (2009), areas with disorders of the fiber structure such as dislocations or microcompressions behaved more elastically. Alexander and Marton (1968) stated that when it comes to dislocations, refining affects the latewood fibers more strongly. Watson and Dadswell (as cited by McIntosh and Uhrig 1968) pointed out that because of their more rigid nature, latewood fibers are damaged more during refining than the earlywood fibers. Thirdly, increased swelling and reduced axial stiffness have been named as causes of higher drying shrinkage and the consequent higher elongation of paper. However, influence of high consistency treatment on direct tensile properties of individual fibers is poorly known.

Several different fiber deformation types have been named and used in the literature, such as: curl, kinks, crimps, nodes, twists (axial and longitudinal), dislocations (longitudinal and transverse), microcompressions, misaligned zones, slip planes, and angular folds. Some of the deformation types denote similar or identical deformation types, e.g. dislocations, slip plane, and misaligned zone. Node may mean a longitudinal compression where a fiber can bend and form a kink. Mohlin et al. (1996) and Page et al. (1985) have shown that the number of kinks, folds, twists or compressions correlated with the shape factor of pulp and they have an influence on tensile strength, tensile stiffness, stretch to break, and zero-span tensile strength of paper.

The objective of this study was to investigate the effect of small-scale deformations caused by mechanical treatment (refining) of pulps on the tensile behavior, and especially the extensibility of individual fibers and the papers made from those pulps. It is highly significant for the development of new fiberbased packaging products. This investigation was part 
Table 1 Average length weighted fiber properties of the pulps and viscose fibers

\begin{tabular}{lcccc}
\hline & Untreated & HC & HC + LC & Viscose \\
\hline LW fiber length of pulp (mm) (FiberMaster) & 1.83 & 1.87 & 1.80 & \\
LW fiber length of pulp (mm) (Fiber Tester Plus) & 1.73 & 1.66 & 1.22 & 5.54 \\
LW fiber width of pulp ( $\mu \mathrm{m})$ (FiberMaster) & 26.6 & 27.0 & 27.1 & \\
LW fiber width of pulp ( $\mu \mathrm{m})$ (Fiber Tester Plus) & 27.4 & 25.5 & 24.2 & 17.2 \\
Shape factor (\%) (FiberMaster) & 83.7 & 80.3 & 83.3 & \\
Form (shape factor) (\%) (Fiber Tester Plus) & 84.8 & 80.4 & 83.5 & 88.7 \\
Kink per mm (mm & \\
\hline
\end{tabular}

of two larger research projects: 'Tailored fibre-fibre interactions for boosted extensibility of bio-based fibre networks (ExtBioNet)' supported by the Academy of Finland and the 'Advanced Cellulose to Novel Products (ACel)' program of the Finnish Bioeconomy Cluster CLIC Innovation. The objective of both projects was to improve the extensibility of the pulp fiber network for thermoforming applications.

\section{Experimental}

Raw materials

The raw material was a dried bleached softwood kraft pulp (BSKP), a mixture of spruce and pine, from a Nordic pulp mill. The BSKP was soaked overnight in tap water and then disintegrated for 30 min using a Valley beater without load. The BSKP was refined at $40 \%$ solids content (high consistency, HC treatment) using a wing defibrator (WD) exactly according to Khakalo et al. (2017a). WD is a high-intensity single stage batch wood chip refiner equipped with four rotating blades. Additional information on the refining conditions for $\mathrm{HC}$ treatment can be found in Zeng et al. (2013). The HC treatment was followed by Valley beating (LC treatment) according to the standard procedure (SCAN-C 25:76). The same batch of BSKP is described in detail in Khakalo et al. (2017b) and was utilized in Khakalo et al. (2017a) and Kouko et al. (2018). The SR numbers (ISO 5267-1) of the untreated and $\mathrm{HC}+\mathrm{LC}$ treated BSKPs were 12 and 25 and the WRV (ISO 23714) $1.08 \mathrm{~g} / \mathrm{g}$ and $1.47 \mathrm{~g} / \mathrm{g}$, respectively. The SR number of the HC treated BSKP was approximately the same as untreated BSKP, because the influence of the HC treatment on SR number was minor as can be seen from Zeng et al. (2013) and Khakalo et al. (2017a). However, in both studies a clear influence of WD treatment on the average fiber properties of the pulp, e.g. shape factor and kinks, and the strength properties of hand sheets were observed. In this study, the objective was to apply mechanical treatment methods of pulp fibers and chemical strength additives in order to maximize the strength and elongation of individual fibers and sheets. HC treatment of BSKP is known to increase both small and large-scale fiber deformation, whereas LC treatment straightens the fibers without significantly removing small-scale deformations (Seth 2005).

The fiber samples were selected from untreated, HC (high consistency) treated and $\mathrm{HC}+\mathrm{LC}$ (high + low consistency)-treated pulps. Viscose fibers [Kelheim $\mathrm{GmbH}$ (Danufil ${ }^{\circledR}, 1.7$ dTex and staple length $6 \mathrm{~mm}$ )] were used as a reference (see Bernt 2011 for more details). Fiber properties of the pulps were measured using the STFI FiberMaster and L\&W Fiber Tester Plus (the fibers were measured in swollen state). The length weighted (LW) average fiber lengths and widths, as well as the shape factors, are presented in Table 1.

\section{Paper samples}

The pulps were made into $60 \mathrm{~g} / \mathrm{m}^{2}$ hand sheets according to EN ISO 5269-1. All hand sheets were wet pressed at $350 \mathrm{kPa}$ for $5+2 \mathrm{~min}$ with one exception, which is described later. Two drying methods were used to vary the shrinkage of the sheets: restrained drying after wet pressing according to the EN ISO 5269-1 and unrestrained drying between two forming wires that were supported by a grid and separated by a $5 \mathrm{~mm}$ thick rod. The elastic modulus and thus the strain to break of paper is known to vary considerably depending on whether the drying shrinkage is free or restrained, see, e.g., Mäkelä (2009) and Kouko and Retulainen (2018). Untreated and HC 


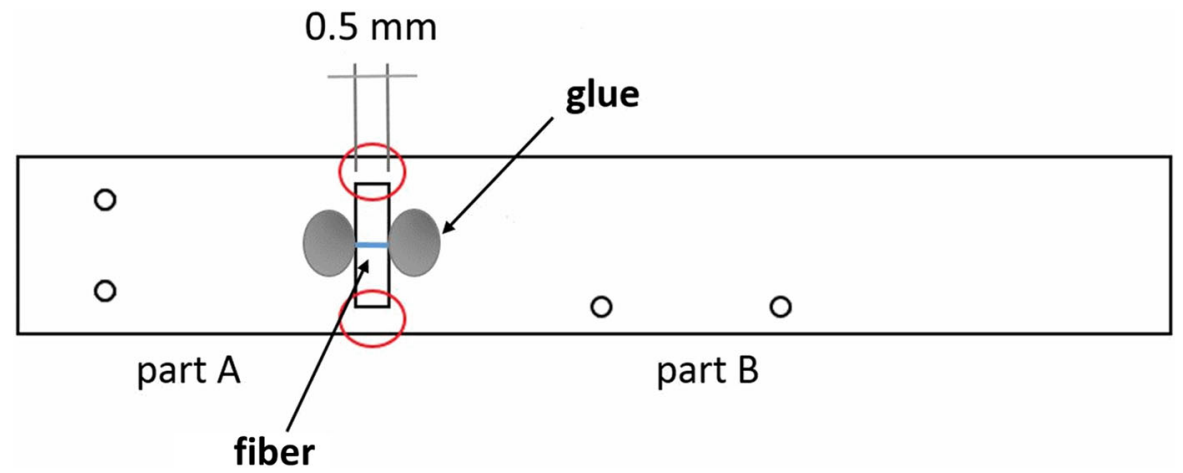

Fig. 1 Sample holder with $500 \mu \mathrm{m}$ gap used for tensile testing

treated BSKP sheets were dried unrestrained and restrained, whereas HC + LC BSKP sheets were only dried unrestrained.

Additionally, high pressure wet pressing and addition of strength chemicals were applied in order to improve bonding of the fibers. A few untreated BSKP sheets were wet pressed using $670 \mathrm{kPa}$ pressure (instead of $350 \mathrm{kPa}$ ) before unrestrained drying. Combination of $1.5 \%$ cationized starch, Cationic polyacrylamide (CPAM) $200 \mathrm{~g} / \mathrm{t}$ and $5 \%$ Masuko micro-fibrillated cellulose (CMF) from VTT (E393HWM3) was added into untreated BSKP and the sheets were dried unrestrained and restrained. The starch Classic 135 was a potato-based wet-end starch with a degree of substitution of 0.035 from Chemigate. The CPAM Fennopol K3400R with a molecular weight of 6-7 million $\mathrm{g} / \mathrm{mol}$ and charge density of $1 \mathrm{meq} / \mathrm{g}$ was obtained from Kemira (Finland). The CMF was prepared from never-dried birch kraft pulp by mechanical disintegration. The dispersed pulp ( $1.7 \%$ consistency) was first pre-refined with a grinder (Supermasscolloider MKZA10-15 J, Masuko Sangyo Co., Japan) at $1500 \mathrm{rpm}$, followed by treatment with a fluidizer (Microfluidics M-7115-30, VTT, Espoo, Finland). The CMF was produced after three passes at an operating pressure of 1800 bar. No chemical modification was applied. The dry cationic starch was diluted in deionized water (conductivity $<1 \mu \mathrm{S} / \mathrm{m}$ ) to a final concentration of $1 \%$ and heated for $30 \mathrm{~min}$ at $90{ }^{\circ} \mathrm{C}$ under constant stirring. The dry CPAM was diluted in deionized water at $0.3 \%$ concentration. The solution was kept under constant stirring until fully dissolved and then further diluted to $0.01 \%$ for actual use. The influence of the addition of a similar CMF to a
BSKP pulp on the shrinkage, extensibility and strength of hand sheets is presented in Ketola et al. (2018).

Testing of the dry sheets took place at a temperature of $23{ }^{\circ} \mathrm{C}$ and at $50 \%$ relative humidity, using a strain rate of $10 \mathrm{~mm} / \mathrm{min}(0.167 \% / \mathrm{s})$ in a Lloyd tensile tester, in accordance with ISO 5270:2012. The thickness and apparent sheet density of the dry paper were measured using ISO 534, and air-dry grammage using ISO 536.

Preparation and identification of single fibers

Fibers for individual testing were prepared following the method described by Kappel et al. (2009). Dry pulp was dispersed and allowed to swell in water for at least $12 \mathrm{~h}$. The fibers were disintegrated according to DIN EN ISO 5263-1. A highly dilute suspension with a consistency of $0.01 \%$ was prepared. Small drops of the suspension were placed on a piece of Teflon foil $(40 \mathrm{~mm} \times 40 \mathrm{~mm})$ and covered with another piece of Teflon foil. This sandwich was dried in a conventional sheet dryer for $45 \mathrm{~min}$. The drying method used allowed shrinkage of the individual fibers. In order to perform single fiber tensile tests, the individual fibers were glued onto the sample holder (Fig. 1) using a two component epoxy resin (UHU PLUS ENDFEST). The sample holder used for the fiber tensile strength testing is described in Lorbach et al. (2014) and Jajcinovic et al. (2016). The gap in the sample holder was $0.5 \mathrm{~mm}$. The span length is known to influence the strength (Hardacker 1970). After gluing of the individual fibers (Fig. 1), they were conditioned for at least $24 \mathrm{~h}$ prior to identification and testing to ensure the maximum holding strength of the resin and moisture equilibrium. The dry BSKP fibers were 
photographed before tensile testing and identified using a Leica DMLM microscope with $50 \times$ magnification and OptiMOS monochrome sensor camera from QImaging and using literature as a reference (Ilvessalo-Pläffli 1995).

The objective was to accept only pulp fibers without axial twisting and visible fractures to the tests. All fibers that were clearly identified as earlywood (springwood) fibers and the fibers with axial twisting, damage, or improper gluing were rejected. After tensile testing, cross-section images revealed that some of the tested fibers were thin-walled (earlywood) fibers, which was not possible to determine from the side-view image. Due to the laborious test procedure, the tensile results of the individual thin-walled and thick-walled fibers were grouped separately.

Determination of single fiber dimensions

from microtome cross sections

The cross sectional area $\left(\mathrm{A}_{\text {cross }}\right)$, fiber width $\left(\mathrm{w}_{\mathrm{f}}\right)$, and fiber thickness $\left(t_{f}\right)$ of single fibers were measured in the dry state from light microscope images, see Figs. $3 b, 4 b, 5 b$ and $6 b$. After tensile testing, the fibers were glued onto paper tabs with a free end protruding out and embedded in a resin. Once the resin was cured, the fibers were cut with a Leica RM 2255 microtome with a cut thickness of $3 \mu \mathrm{m}$ and imaged according to Lorbach et al. (2014). However, it was not possible to do the microtome analysis for all fibers due to the too short length of the broken pieces. In the case of successfully cut fibers, the images were binarized and the area analyzed using Matlab R2014b. From the images (presented in electronic supplementary material), it was possible to divide the tested untreated BSKP fibers into thick-walled and thin-walled fibers using the microtome photographs and a cross-sectional area of $190 \mu \mathrm{m}^{2}$ as a limit.

Determination of single fiber width using fiber images

Due to the too short length of the broken pieces, it was not possible to do the analysis for all fibers. The image analysis of width-length direction photographs, see Figs. 3a, 4a, 5a and $6 a$, was used for producing the fiber width data for all the measured fibers. The photographs were first changed to black and white $(\mathrm{B} \& \mathrm{~W})$ images and the fiber edges were slightly smoothed. Then image analysis software was used to measure the width of the fibers (pixel by pixel along the fiber length) and calculate the average fiber width. A reference image of a ruler was used for defining the length scale. The averages of the calculated fiber widths are presented in Table 2 .

Cleavage test of pulp fibers

A cleavage test using hydrochloric acid $(\mathrm{HCl})$ treatment developed by Ander et al. $(2005,2008)$ and slightly modified by Zeng et al. (2012) was used as an estimate for the number of fiber dislocations in the pulps and viscose fibers. The treatment presumably cuts the fibers at the dislocation areas, which have higher accessibility to the acid and can be considered as weak points in fibers. The arithmetic (AR) fiber lengths that were utilized in the calculation of cleavage index were measured using the STFI FiberMaster after setting the lower length limit of fibers to 44 from $200 \mu \mathrm{m}$. The cleavage results are presented in Table 3.

Single fiber tensile testing

The single fiber tensile testing was performed using the fiber bond tester at TU Graz (Fischer et al. 2012; Lorbach et al. 2014; Jajcinovic et al. 2016). Off-set force was measured prior to the test and then a minor preliminary loading was applied to fiber. A displacement measurement system (shown in Fig. 2) was attached to the fiber bond tester in order to measure load-elongation data of the single fiber tensile tests. The displacement of the tension support was measured using a laser displacement sensor (Micro-epsilon OptoNCDT LD 1605-10, with a resolution of $3 \mu \mathrm{m}$ ). The displacement data was recorded using a National Instruments data logger system. The velocity of the moveable support of the fiber bond tester turned out to be very stable within the measurement accuracy of the laser sensor and therefore the linear fit of each measured displacement as a function of time was used in order to decrease the noise of the displacement data. The load data recorded by the fiber bond tester was complemented by the displacement data as a function of time in the data analysis afterwards. Both data were measured at $1 \mathrm{kHz}$ frequency.

Sample holder mounting was performed as described by Lorbach et al. (2014) and Jajcinovic 


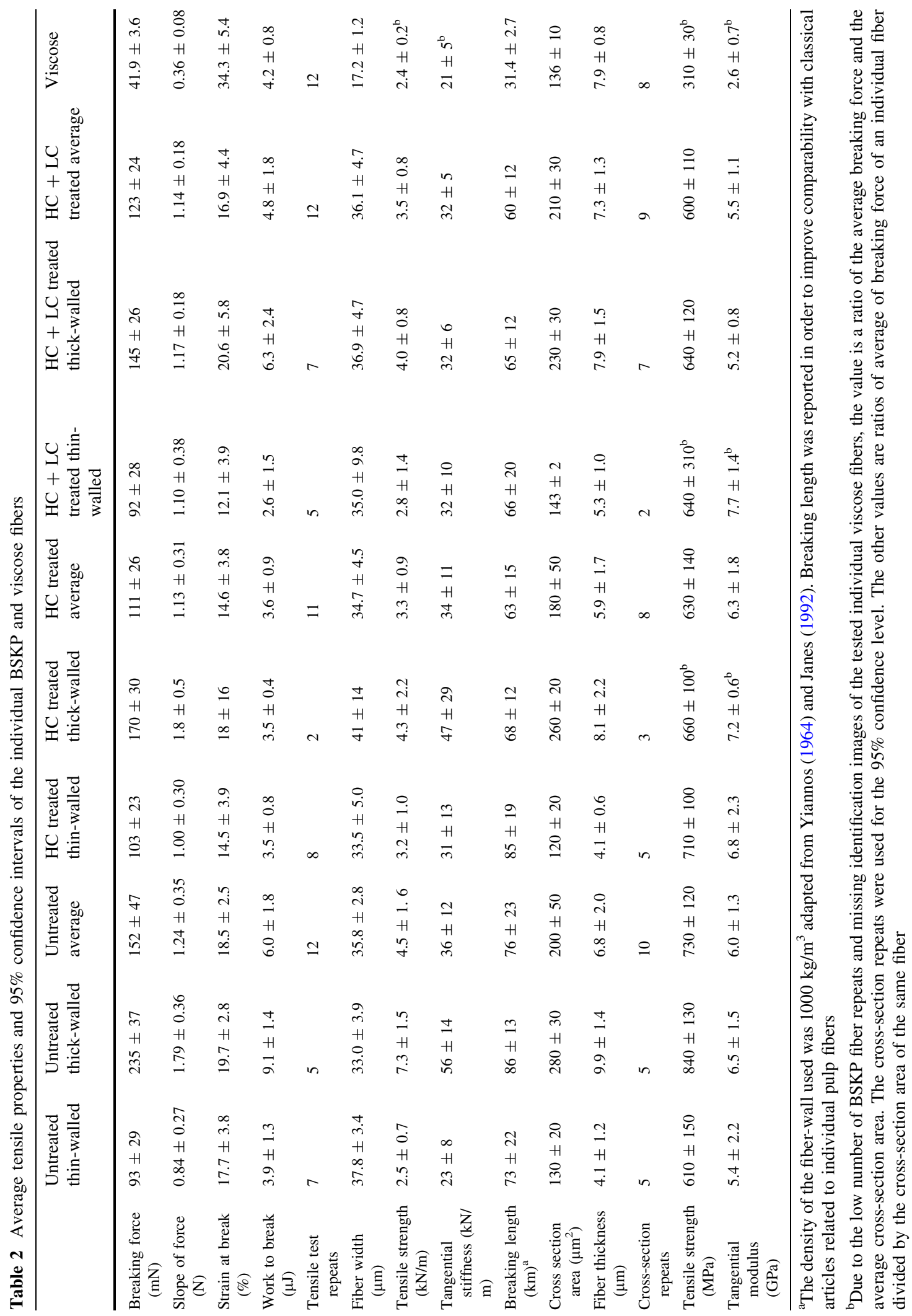


Table 3 Fiber cleavage of BSK pulps and a viscose fiber suspension

\begin{tabular}{lllll}
\hline & Untreated & HC treated & HC + LC treated & Viscose \\
\hline LW fiber length of pulp (mm) & 1.83 & 1.87 & 1.80 & 0.58 \\
AR fiber length of pulp (mm) & 0.63 & 0.64 & 0.26 & 2.07 \\
AR fiber length of HCl-treated (mm) & 0.32 & 0.24 & 1.21 & 0.72 \\
Cleavage (per fiber) & 1.01 & 1.57 & 2.08 & 0.94 \\
Cleavage index (arithmetic) $\left(\mathrm{mm}^{-1}\right)$ & 1.58 & 2.50 & & 05 \\
\hline
\end{tabular}

$L W$ length weighted, $A R$ arithmetic mean

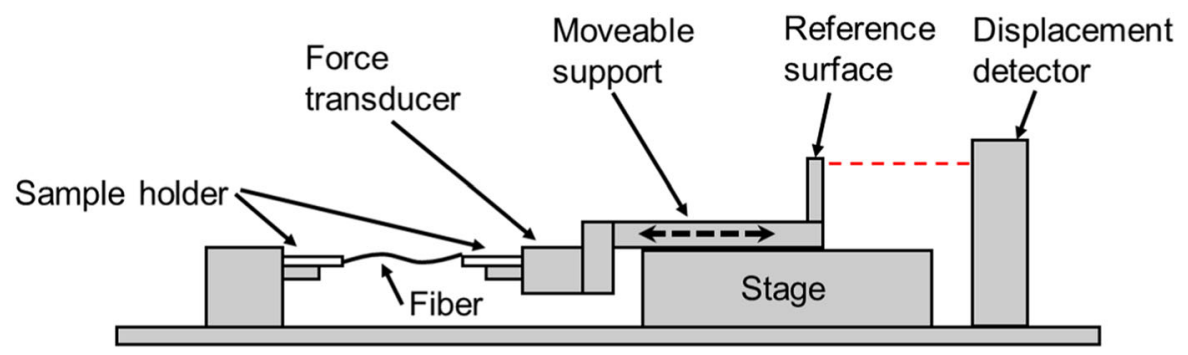

Fig. 2 Schematic image of the fiber bond tester with the laser displacement detection system

et al. (2016). The sample holder was placed under a light microscope, which was equipped with a digital camera (Fischer et al. 2012) and a computer monitor. The tensile test was recorded with the imaging system, which enabled rejection of the tests in which gluing failed. The fibers were strained until break at $1 \mu \mathrm{m} / \mathrm{s}$ elongation speed $(0.2 \% / \mathrm{s}$ strain rate). The initial part of the force-strain curve was not recorded due to pretensioning of the fiber before the test. The initial strain that corresponded to the initial force was calculated using the initial slope (initial tangential modulus) of the force-elongation curve. All tests were performed in a climate room at $23{ }^{\circ} \mathrm{C}$ temperature and $50 \%$ relative humidity.

The primary data obtained from the single fiber tensile test were load and displacement data. Tensile strength $\left(\sigma_{f}\right)$ in MPa units (Eq. 1) corresponding to the break load $\left(\mathrm{F}_{\text {break }}\right)$ was calculated using the measured fiber cross-sectional area $\left(\mathrm{A}_{\text {cross }}\right)$ of each fiber.

$\sigma_{f}=\frac{F_{\text {break }}}{A_{\text {cross }}}$

As the fibers exhibit non-linear stress-strain behavior, the tangential stiffness and tangential modulus values were chosen to present the maximum slope of the tensile curve of the individual fiber. Tangential stiffness and modulus were calculated as the maximum slope of the load-strain curve of a single fiber divided by the width or the cross-directional area $\left(\mathrm{A}_{\text {cross }}\right)$, respectively. Tangential slopes, covering all stress-strain data until breaking, were calculated by applying a moving average slope over a constant strain range of $0.6 \%$. The resulting tangential slope was an average at the region of the highest slope. The maximum of the slope on the load-strain curve of a single fiber was defined as force tangent modulus and here denoted simply by $\mathbf{M}_{\mathrm{f}}$. In this investigation, the tangential modulus $\left(\mathrm{E}_{\mathrm{f}}\right)$ (Eq. 2) of a single fiber was obtained by dividing the $\mathrm{M}_{\mathrm{f}}$ by the fiber crosssectional area $\left(\mathrm{A}_{\text {cross }}\right)$.

$E_{f}=\frac{M_{f}}{A_{\text {cross }}}$

\section{Results}

Characteristic images of the studied fibers

Figures 3, 4, 5 and 6 present photograph examples of the tested fibers: sub-figures denoted (a) present length-width direction and sub-figures denoted 

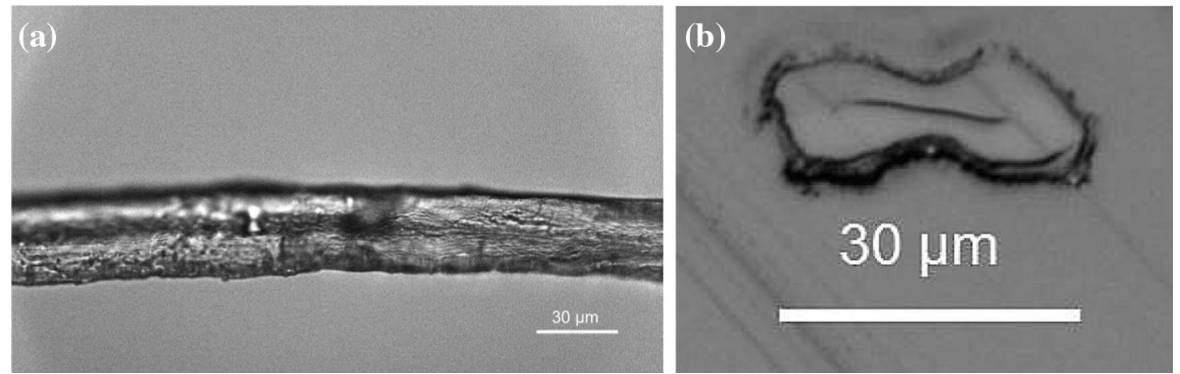

Fig. 3 Untreated bleached softwood kraft fiber (\#14): a visible dislocations and microcompressions, b collapsed cross-section of this thick-walled BSKP fiber. Width $33.4 \mu \mathrm{m}$, thickness $9.35 \mu \mathrm{m}$, cross-section area $276 \mu \mathrm{m}^{2}$, breaking force $300 \mathrm{mN}$
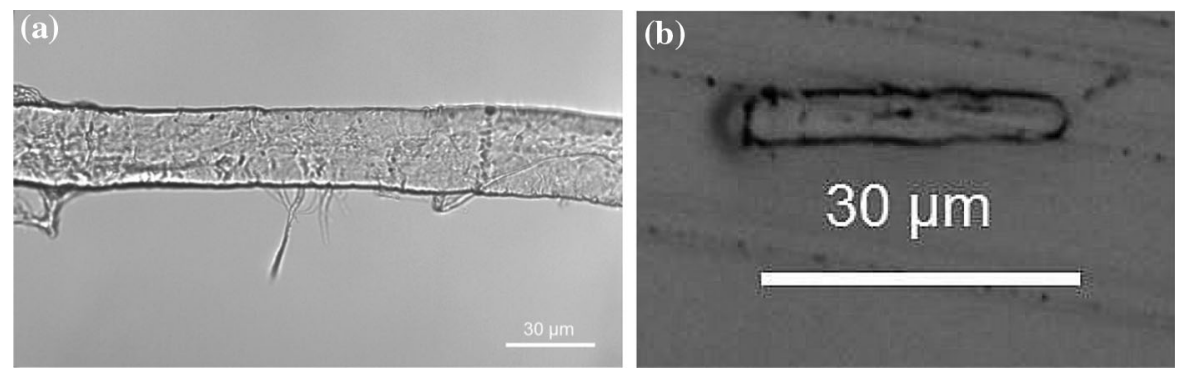

Fig. 4 HC treated bleached softwood kraft fiber (\#6): a external fibrils and a possible longitudinal dislocation, b collapsed crosssection of this relatively thin-walled BSKP fiber. Width $30.3 \mu \mathrm{m}$, thickness $4.7 \mu \mathrm{m}$, cross-section area $140 \mu \mathrm{m}^{2}$, breaking force $87 \mathrm{mN}$
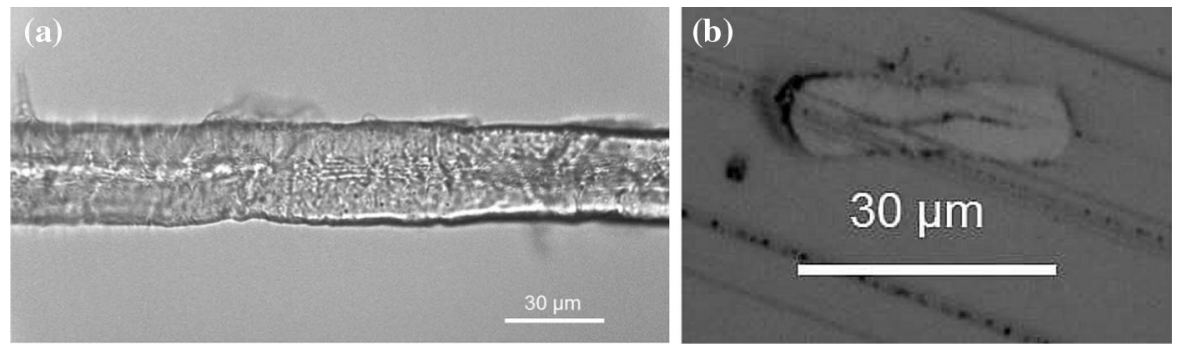

Fig. $5 \mathrm{HC}+\mathrm{LC}$ treated bleached softwood kraft fiber (\#3): a external fibrils and longitudinal dislocations and microcompressions, $\mathbf{b}$ collapsed cross-section of thick-walled BSKP fiber.

(b) present cross-section images of the fibers. The microscope images of the fiber cross-sections showed that the lumen of all studied BSKP fibers was completely collapsed, whereas the viscose fibers did not have a lumen. The images of the other tested fibers are presented in the electronic supplementary materials S1-S4. A major finding from the individual fiber images was that the untreated BSKP fibers already had a significant number of dislocations.
Width $33.2 \mu \mathrm{m}$, thickness $9.3 \mu \mathrm{m}$, cross-section area $294 \mu \mathrm{m}^{2}$, breaking force $121 \mathrm{mN}$

Characteristic dimensions of the individual fibers

Characterization of fiber cross-sectional properties (thickness, cross-section area and collapse) is generally difficult using only the fiber width. However, inspecting cross-section area and fiber thickness reveals that a cross-section area of $190 \mu^{2}$ approximately divides the fibers into thin- and thick-wall classes (see Figures in supplementary material S1). Accordingly, fibers with a cross-sectional area greater 

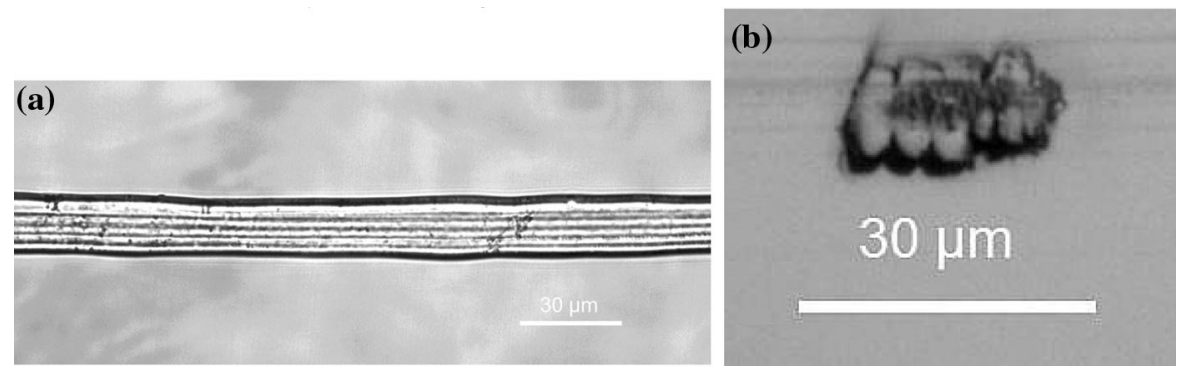

Fig. 6 Viscose fiber: a smooth and straight structure, $\mathbf{b}$ cross-section
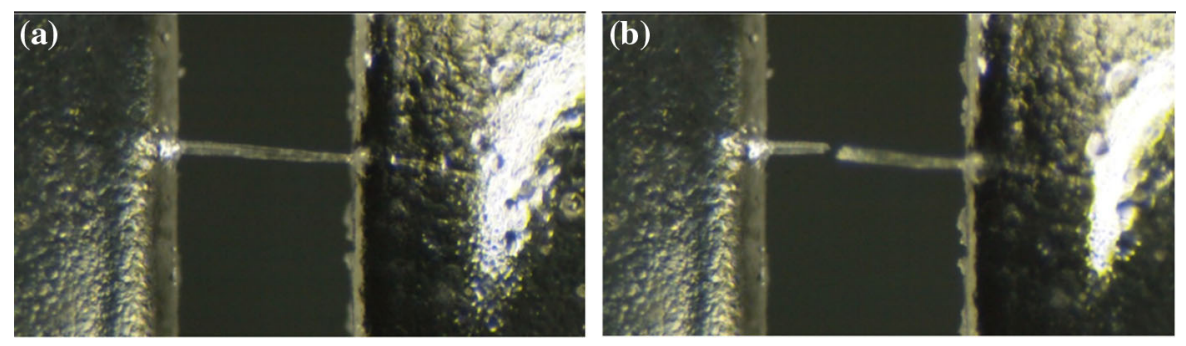

Fig. 7 Tensile test of untreated BSKP fiber: a the fiber mounted in the tester before the test, $\mathbf{b}$ the tested fiber after the test

than $190 \mu \mathrm{m}^{2}$ were classified as thick-walled fibers. The average dimensions of the investigated individual fibers are presented in Table 3. The number of repeats was low for some classes, but the validity of the classification can be verified from the images supplied in the electronic supplementary material S1-S3.

Illustration of single fiber tensile test

The tensile test of individual untreated BSKP fiber is described in Fig. 7. Figure $7 \mathrm{a}$, b present the fiber mounted in the tester before and after the test. The force-strain curve of the individual untreated BSKP fiber was concave upwards, i.e., the slope increased as a function of strain. The breaking force of the individual fiber was $160 \mathrm{mN}$, which was close to the reported value for latewood fiber of softwood kraft pulp (192 mN and $206 \mathrm{mN}$ for Scots pine and Norway spruce respectively, see Table 1 in the Supplementary material S1). The strain at break of the fiber was $20 \%$, which was high compared to the reported values for similar softwood pulp fiber (see Table 1). Side and cross-section microscope images and the force strain curves of all measured softwood fibers are presented in the electronic supplementary materials S1-S3.
Average tensile properties of the tested individual BSKP fibers are presented in Table 2 and Fig. 8a, b. The untreated, HC and HC + LC treated BSKP fibers were classified as thin-walled, thick-walled and average (containing the two previous) groups using the cross-section images and areas. The number of repeats was low for some classes (e.g., HC treated thickwalled BSKP fiber). However, the relevance of the classification can be verified from the electronic supplementary materials S1-S3.

\section{Thick-walled fibers versus thin-walled fibers}

Strain at break, breaking force, slope of force, and work to break of thick-walled fibers were significantly higher compared to the respective values of thinwalled fibers, which is according to expectations. HC and $\mathrm{HC}+\mathrm{LC}$ treatment decreased the breaking force of thick-walled fibers and did not affect the average breaking force of thin-walled BSKP fibers. Also, the observed reduction in breaking force due to the mechanical treatment is an expected result. There are clear differences between the tensile properties of thick-walled and thin-walled fibers. 

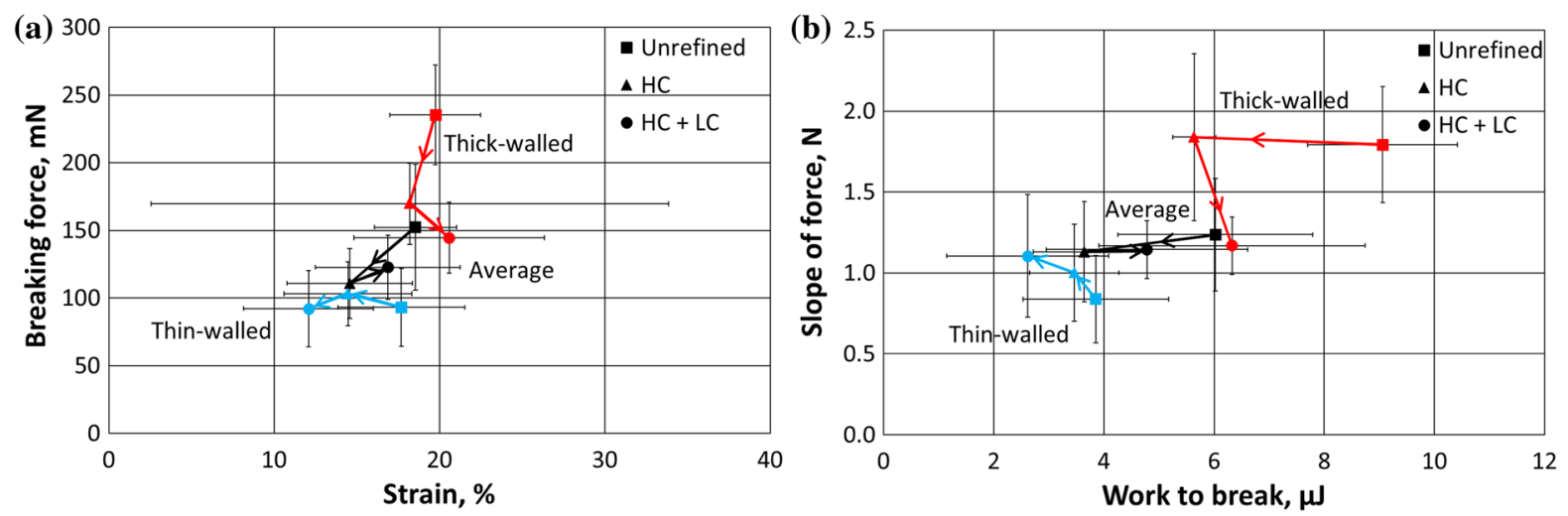

Fig. 8 a Breaking force over breaking strain and b slope of force over work to break with $95 \%$ confidence intervals plotted from the data in Table 2. The arrows show the influence of increasing mechanical treatment

Fiber elongation

The high elongation values obtained for the BSKP fibers are higher that the most results presented in the literature. However, these fibers were from industrial pulp and gone through harsher treatments than laboratory processed pulps. Additionally the BSKP was made of chips from younger trees originating from thinnings that typically have higher fibril angle fibers (Groom et al. 2002). Elongation at break of thickwalled fibers was not significantly changed by the mechanical treatments, only the variance grew.

On the other hand, strain at break of thin-walled fibers decreased from the original $17.7 \%$ value to $14.5 \%$ and $12.1 \%$ due to the $\mathrm{HC}$ and $\mathrm{HC}+\mathrm{LC}$ treatments, respectively. The microscope photographs (see electronic supplementary material S1-S3) show that the investigated untreated BSKP fibers had a significant amount of small-scale deformations, which was slightly unexpected. Elongation of the viscose fiber, at $34.3 \%$, was significantly higher compared to the BSKP fibers. Unexpectedly, the individual BSKP fiber elongation was not improved after the mechanical treatments.

Fiber tangential stiffness

The tangential moduli of average BSKP fibers (containing thin- and thick-walled fibers) were in quite a narrow range from 5.5 to $6.3 \mathrm{GPa}$, but the values were also only $30-50 \%$ of the values presented from the literature in Table 1 in the supplementary material S1. The mechanical HC treatment seemed to improve the tangential modulus of thin- and thick-walled fibers (Table 2). However, the subsequent mechanical LC treatment reduced the tangential moduli of the thickwalled BSKP fibers, whereas the tangential moduli of the thin-walled BSKP fibers were slightly improved. Microfibril angle (MFA) has been reported to dictate the elastic moduli of thin-walled (presumably earlywood) and thick-walled (presumably latewood) fibers (Schniewind 1966; Borodulina et al. 2015). Therefore, the investigated fibers may also have contained varied microfibril angles. Tangential modulus of the viscose fibers was 2.6 GPa, which was less than half that of the BSKP fibers. Unexpectedly, the influence of mechanical treatment on BSKP fibers' tangential stiffness was small.

\section{Individual fiber strength}

The $\mathrm{HC}$ and $\mathrm{HC}+\mathrm{LC}$ treatments decreased the tensile strength of BSKP pulp fibers on average, but the decrease concentrated on the thick-walled fibers, whereas strength changes of thin-walled fibers were within the $95 \%$ confidence intervals. Tensile strength in MPa units (force scaled with the cross-section area) of the BSKP fibers varied from 600 to $840 \mathrm{MPa}$, which is comparable to the results obtained in other studies (Hardacker and Brezinski 1973; Duncker and Nordman 1965; Page et al. 1972; Groom et al. 2002). The origin of the fiber strength is the strength of natural cellulose I polymer in the cell wall. A few estimates, varying from 297 to $800 \mathrm{MPa}$, have been given for the strength of crystalline and amorphous cellulose I polymer (Zeng et al. 2013; Lundahl et al. 2016), but on 
the other hand the strength of cellulose should probably be greater than the strength of BSKP fiber. The tensile strength $(310 \mathrm{MPa})$ of the viscose fibers, which are formed from cellulose II polymer chains, was less than half of that of the BSKP fibers. However, according to Bledzki and Gassan (1999), the mechanical properties of the man-made cellulosic fibers depend on their structure on different levels, and the tensile strength of viscose fibers has been shown to be strongly influenced by the length of molecules and straining in the manufacturing process. The lower tangential stiffness and the higher plasticity of viscose fibers, in respect to the BSKP fibers (shown in Fig. 10a-d), are some of the probable reason for the higher elongation and lower strength. The BSKP fibers contained some visible small-scale deformation and because of the removed lignin and hemicellulose (from the inner cell walls $S_{1}$ and $S_{2}$ ), their fiber-wall was possibly more porous than that of viscose fiber. The small-scale deformations in the BSKP fibers did not seem to have any role for the strength in comparison to the structurally more homogeneous viscose fibers. As expected, a clear decrease in BSKP fiber strength was observed due to the mechanical treatments. On the other hand, the observed decrease in work to break (i.e. toughness) due to the mechanical treatment on BSKP was unexpected.

\section{Cleavage of fibers}

A cleavage test using $\mathrm{HCl}$ treatment was used to estimate the number of fiber defects (Ander et al. 2005, 2008; Zeng et al. 2012). The $\mathrm{HCl}$ treatment mainly cuts the fibers at the dislocation areas, which can be considered as weak points in the fibers. The high consistency (HC) treatment of BSKP increased the cleavage and the LC treatment reduced the cleavage, as presented in Table 3. Both breaking force and elongation of the BSKP fibers formed a linear relation with negative slope as a function of cleavage index and with each other as shown in Fig. 9. This suggests that both, fiber strength and fiber extensibility decrease with increasing mechanical treatment due to fiber damage. Additionally, the results indicate that the cleavage test may be a useful indirect method of estimating the influence of mechanical treatments on the strength and elongation of individual pulp fibers. Surprisingly, the viscose fibers showed several cleavages per fiber. However,

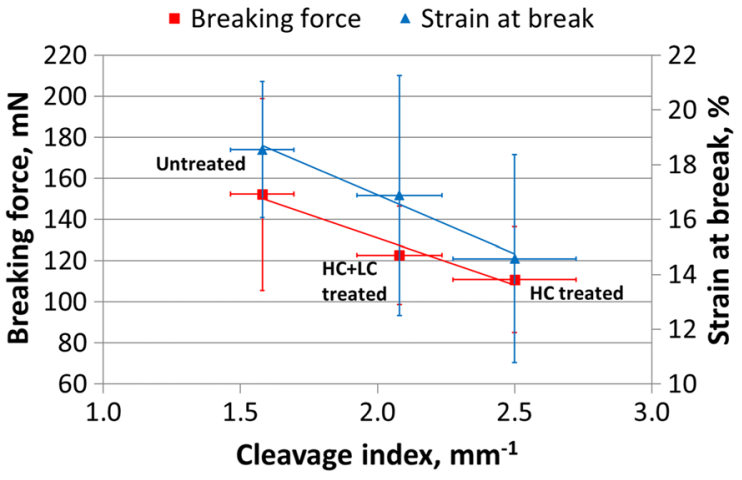

Fig. 9 Breaking force and strain at break of the single BSKP fibers as a function of cleavage index of the pulps with $95 \%$ confidence intervals

the number of cleavages per length-unit in viscose fiber was lower compared to BSKP. Results indicate that viscose fibers are less homogenous than expected and may also exhibit defects. Also the mechanically untreated BSKP fibers had a significant number of cleavages per fiber.

Stress-strain curves of the fibers

Stress-strain curves of the individual fibers are presented in Fig. 10a-d. Stress-strain curves of thick-walled fibers are presented in red and thinwalled in light blue. The markers with the $95 \%$ confidence intervals present average values of thickwalled, thin-walled, and all fibers according to Table 3. All force-strain curves of the individual fibers are presented in the electronic supplementary material S1-S4.

The tensile curves of the individual untreated BSKP fibers (Fig. 10a) were either smoothly and bi-linearly concave upward, apparently linear, or slightly concave downward, but none of them were highly concave downward, which is a typical shape for a tensile curve of paper (see Fig. 11a, b). The larger parts of the tensile curves were formed from two or even three phases that were mostly slightly concave upward. Increasing slopes may indicate the presence of dislocations or other fiber deformations, which were pulled straight during tensile testing. The large variation between the single BSKP fiber stress-strain curves in terms of shape, in addition to the variation of elongation from 10 to $32 \%$, can also be regarded as an important finding. The single fiber tensile curves 

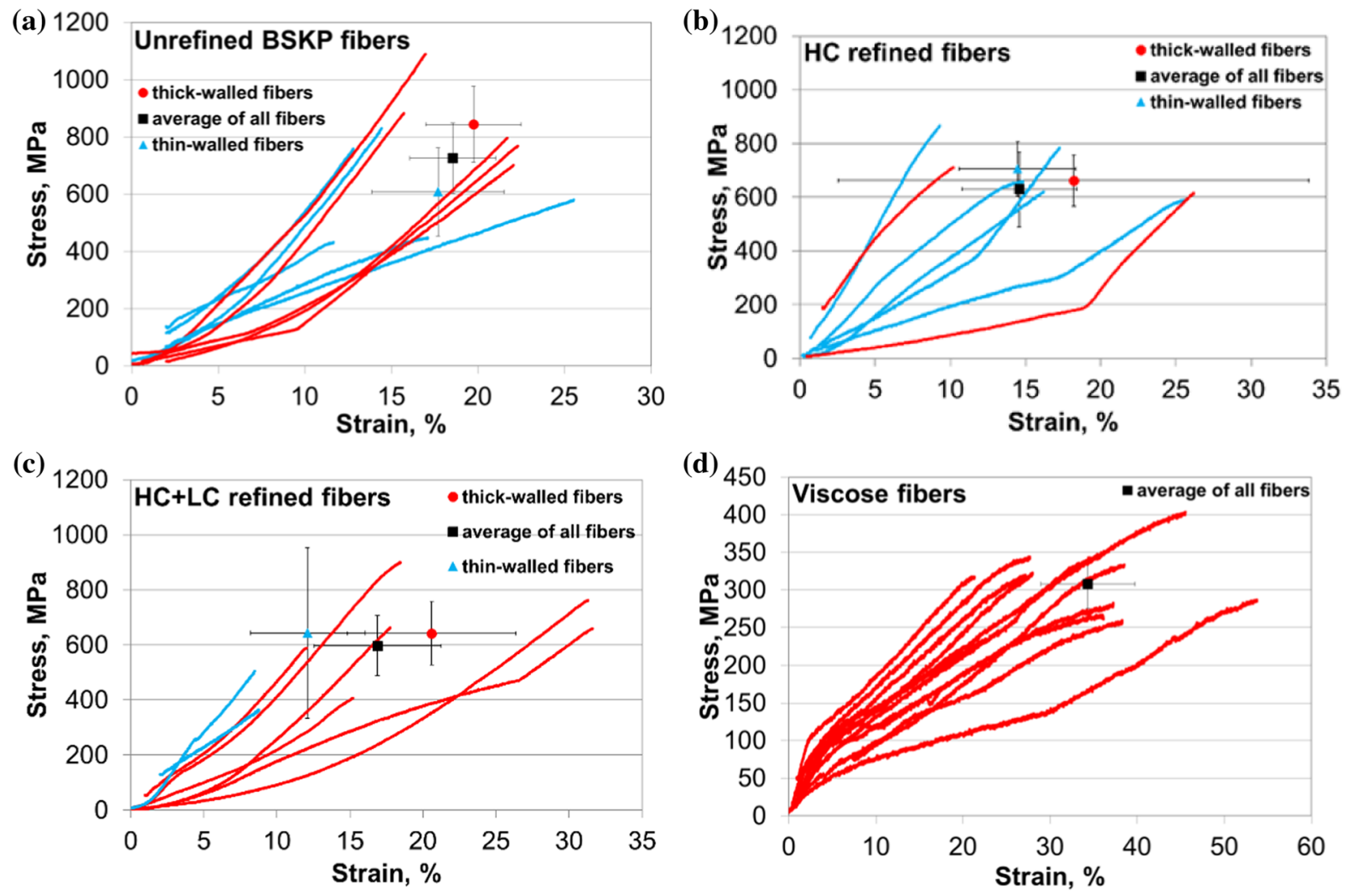

Fig. 10 Stress-strain curves the tested fibers: a unrefined BSKP, b HC refined BSKP, c HC + LC refined BSKP, d viscose
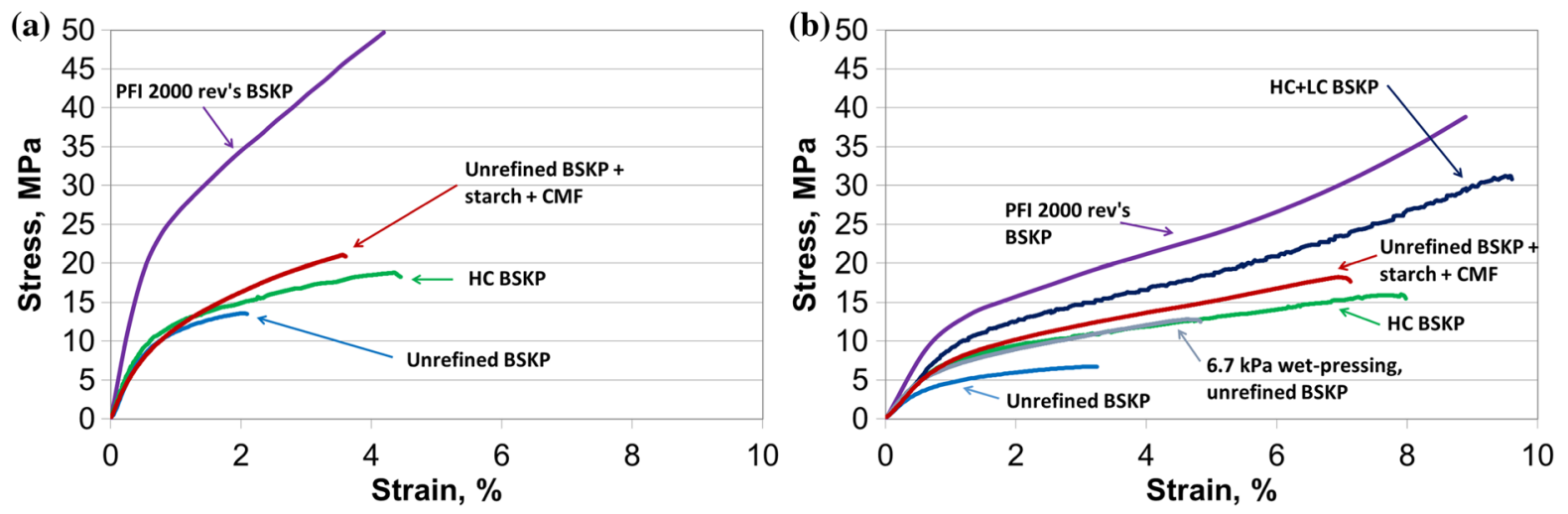

Fig. 11 Stress-strain curves of the tested BSKP hand sheets with restrained (a) and unrestrained drying (b). PFI 2000 rev. curves of the same BSKP from courtesy of Khakalo (additional information can be found from Khakalo et al. 2017a)

presented in the literature have typically been apparently linear or slightly concave downward (Kallmes and Perez 1965a, b; Van den Akker et al. 1965; Hardacker and Brezinski 1973; Groom et al. 2002, Mott et al. 2002), whereas the concave upward shape has been especially rare. In summary, unexpectedly only a few of the individual BSKP fiber tensile curves were apparently linear and elongation range from 3 to $6 \%$ was absent, which is the typical elongation in the classical literature references reviewed. Unexpectedly, in this work, none of the individual BSKP fiber 
tensile curves were similar to the typical concave downward shape of a paper sheet.

The shape of the stress-strain curve of the viscose fibers also varied considerably, but to a much smaller extent than the pulp fibers (Fig. 10d). Tensile curves of viscose fibers typically consisted of three phases, i.e., an initial phase with steep slope was followed by a concave downward or concave upward phase and the last phase was concave downward. The strain at break of the viscose fibers varied from 20 to $50 \%$, which was larger than expected. However, the variation of breaking force of viscose fibers was clearly smaller than that of the BSKP fibers. The relatively small variation of the breaking force of viscose fibers compared to BSKP fibers may be caused by the less heterogeneous cross-section area and the smaller number of defects.

Tensile properties of fiber networks

Tensile tests were performed for both BSKP sheets dried under restraint and without restraint. The tensile test results are presented in Table 4 and the stressstrain curves in Fig. 11a, b. There was a large difference in the tensile stiffness and elongation at break values between the restrained and unrestrained dried sheets. This can be contributed to the difference in drying shrinkage.

Unrefined pulps gave the lowest strength and elongation at break values. Increased inter-fiber bonding by application of starch and cellulose microfibrils (CMF) and utilization of higher wet pressing pressure of the unrefined pulp improved elongation and tensile strength significantly and close to those of the HC refined pulps, which had approximately only 1 percentage point higher elongation. However, increasing the number and area of fiber contacts by increasing the wet pressing pressure may be connected to water removal and is therefore limited. Applying LC refining to $\mathrm{HC}$ refined pulp increased both strength and elongation further. LC refining is known to make the fibers more straight and increase fiber swelling and subsequent shrinkage (Zeng et al. 2012, 2013).

The HC + LC treatment in combination with unrestrained drying yielded the best elongation of 9.3\% and tensile strength of $30 \mathrm{MPa}$ of the studied BSKP samples, whereas in the case of individual fibers, the untreated BSKP fibers, on average, yielded the best results. For unrestrained drying the stressstrain curves indicate that the increase in strain is more due to an increase in bonding and less to dislocations and other fiber deformations. Unexpectedly, the results show that fiber bonding has an important role not only in determining the strength but also the elongation of fiber networks, which is in accordance with Seth (2005) and its references. In other words, a large increase in elongation can be reached only by strengthening fiber-fiber bonding (as demonstrated by the sheets with starch and CMF). Also, LC refining with 2000 revolutions in the PFI mill raised sheet extensibility to levels similar to $\mathrm{HC}$ and $\mathrm{HC}+\mathrm{LC}$ treatment in the case of both drying methods (unrestrained and restrained). This is untypical, as $\mathrm{HC}$ refining usually results in higher elongation at break (see e.g. West 1964).

The results suggest that $\mathrm{HC}$ refining can have a small positive effect on the elongation of paper but not on the elongation at break of single fibers. This apparent contradiction may be due to the fact that the stress individual fibers are subjected to in paper is, on average, much lower than their fracture stress. Paper fracture is determined by factors related to the development of stress concentrations that trigger the final failure in the fiber network. Nevertheless, the results indicate that microcompressions and ultimate strain at break of individual fibers may play a smaller role in sheet extensibility than has been previously believed.

The result show that high elongation of paper can be promoted by enabling shrinkage of the fiber network and securing high bonding ability of fibers. Additionally, unrestrained drying seems to be much more effective tool for increasing paper extensibility than the fiber deformations caused by mechanical treatment. As a summary, unrestrained drying of BSKP fiber sheets in combination with increased fiber bond strength may be a promising approach for increasing paper extensibility.

\section{Conclusions}

The tensile tests of individual fibers and paper sheets from bleached kraft pulp containing Scots pine (Pinus sylvestris) and Norway spruce (Picea abies) were conducted in order to investigate the effect of small- 
Table 4 Average tensile properties and 95\% confidence intervals of the BSKP sheets

\begin{tabular}{|c|c|c|c|c|c|c|c|c|}
\hline & $\begin{array}{l}\text { Untreated } \\
\text { BSKP } \\
\text { restrained }\end{array}$ & $\begin{array}{l}\text { Untreated } \\
\text { BSKP } \\
\text { unrestrained }\end{array}$ & $\begin{array}{l}\text { HC BSKP } \\
\text { restrained }\end{array}$ & $\begin{array}{l}\text { HC BSKP } \\
\text { unrestrained }\end{array}$ & $\begin{array}{l}\mathrm{HC}+\mathrm{LC} \\
\text { BSKP } \\
\text { unrestrained }\end{array}$ & $\begin{array}{l}\text { Untreated } \\
\text { BSKP, } \\
\text { starch, } \\
\text { CMF } \\
\text { restrained }\end{array}$ & $\begin{array}{l}\text { Untreated } \\
\text { BSKP, } \\
\text { starch, CMF } \\
\text { unrestrained }\end{array}$ & $\begin{array}{l}\text { Untreated } \\
\text { BSKP } 6.7 \mathrm{kPa} \\
\text { wet pressing } \\
\text { unrestrained }\end{array}$ \\
\hline $\begin{array}{l}\text { Tensile } \\
\text { strength } \\
(\mathrm{kN} / \mathrm{m})\end{array}$ & $1.65 \pm 0.04$ & $1.05 \pm 0.06$ & $2.11 \pm 0.02$ & $1.90 \pm 0.74$ & $3.54 \pm 0.15$ & $2.53 \pm 0.10$ & $2.36 \pm 0.28$ & $1.42 \pm 0.08$ \\
\hline $\begin{array}{l}\text { Tensile } \\
\text { strength } \\
\text { (MPa) }\end{array}$ & $13.6 \pm 0.5$ & $6.4 \pm 0.2$ & $19.0 \pm 0.2$ & $15.6 \pm 0.6$ & $30.0 \pm 1.8$ & $21.0 \pm 0.8$ & $17.5 \pm 2.1$ & $12.3 \pm 0.7$ \\
\hline $\begin{array}{l}\text { Tensile } \\
\text { index } \\
(\mathrm{Nm} / \mathrm{g})\end{array}$ & $25.2 \pm 0.9$ & $15.2 \pm 0.5$ & $33.2 \pm 0.4$ & $27.5 \pm 1.1$ & $53.1 \pm 2.3$ & $40.6 \pm 1.5$ & $37.2 \pm 4.2$ & $24.6 \pm 1.4$ \\
\hline $\begin{array}{l}\text { Tensile } \\
\text { stiffness } \\
(\mathrm{kN} / \mathrm{m})\end{array}$ & $270 \pm 30$ & $140 \pm 40$ & $289 \pm 9$ & $147 \pm 16$ & $129 \pm 6$ & $244 \pm 19$ & $137 \pm 7.0$ & $140 \pm 6$ \\
\hline $\begin{array}{l}\text { Tensile } \\
\text { modulus } \\
(\mathrm{GPa})\end{array}$ & $2.21 \pm 0.11$ & $0.86 \pm 0.04$ & $2.60 \pm 0.08$ & $1.21 \pm 0.13$ & $1.09 \pm 0.03$ & $2.03 \pm 0.16$ & $1.02 \pm 0.05$ & $1.21 \pm 0.06$ \\
\hline $\begin{array}{l}\text { Strain at } \\
\text { break }(\%)\end{array}$ & $2.12 \pm 0.18$ & $3.02 \pm 0.18$ & $4.31 \pm 0.18$ & $7.78 \pm 0.21$ & $9.25 \pm 0.26$ & $3.65 \pm 0.30$ & $6.2 \pm 1.1$ & $4.76 \pm 0.18$ \\
\hline $\begin{array}{l}\text { Work to } \\
\text { break } \\
(\mathrm{mJ})\end{array}$ & $39.5 \pm 4.8$ & $35.7 \pm 3.1$ & $103.6 \pm 5.1$ & $157.7 \pm 8.9$ & $291 \pm 24$ & $94.3 \pm 9.3$ & $154 \pm 34$ & $71.4 \pm 5.2$ \\
\hline $\begin{array}{l}\text { Tensile test } \\
\text { repeats }\end{array}$ & 10 & 10 & 10 & 10 & 5 & 10 & 10 & 10 \\
\hline $\begin{array}{l}\text { Sample } \\
\text { thickness } \\
(\mu \mathrm{m})\end{array}$ & 121 & 163 & 111 & 122 & 118 & 120 & 135 & 115 \\
\hline $\begin{array}{c}\text { Sample } \\
\text { width } \\
(\mathrm{mm})\end{array}$ & 15 & 15 & 15 & 15 & 15 & 15 & 15 & 15 \\
\hline $\begin{array}{l}\text { Grammage } \\
\left(\mathrm{g} / \mathrm{m}^{2}\right)\end{array}$ & 65.5 & 68.9 & 63.6 & 69.1 & 66.6 & 62.2 & 63.3 & 57.5 \\
\hline $\begin{array}{l}\text { Density } \\
\left(\mathrm{kg} / \mathrm{m}^{3}\right)\end{array}$ & 541 & 423 & 573 & 566 & 564 & 518 & 469 & 500 \\
\hline $\begin{array}{l}\text { Cross } \\
\text { section } \\
\text { area } \\
\left(\mathrm{mm}^{2}\right)\end{array}$ & 1.82 & 2.45 & 1.67 & 1.83 & 1.77 & 1.80 & 2.03 & 1.73 \\
\hline $\begin{array}{l}\text { Breaking } \\
\text { length } \\
\left(\mathrm{km}^{\mathrm{a}}\right)\end{array}$ & $2.57 \pm 0.09$ & $1.55 \pm 0.05$ & $3.38 \pm 0.04$ & $2.81 \pm 0.11$ & $5.42 \pm 0.33$ & $4.14 \pm 0.16$ & $3.80 \pm 0.45$ & $2.51 \pm 0.14$ \\
\hline
\end{tabular}

$\overline{{ }^{a} \text { Breaking length values were reported in order to have improved comparability to classical articles related to individual pulp fibers }}$

scale deformations caused by mechanical treatment (refining) on tensile behavior.

The measured strength and elongation of individual BSKP fibers ranged from 200 to $1100 \mathrm{MPa}$, and from 8 to $32 \%$, respectively. Only a few of the individual BSKP fiber tensile curves were apparently linear.
More often the slope of the stress strain-curves increased with straining which behavior could be related to the straightening of disordered regions in the fiber wall. None of the individual BSKP fiber tensile curves was similar to the typical concave downward shape of paper sheet. 
The individual BSKP fiber elongation was not improved by the $\mathrm{HC}$ refining and a decrease in strength was observed. The influence of mechanical treatment on fiber tangential stiffness was small. The effects of the refining seemed to correlate with the number of dislocations (measured using $\mathrm{HCl}$ cleavage test) in fibers. With increasing number of dislocations both the average breaking stress and strain decreased. The mechanically untreated BSKP fibers already had a high number of dislocations based on the microscope images and $\mathrm{HCl}$ cleavage test. High consistency refining introduced additional dislocations, but low consistency refining seemed to be able heal some of them. There were clear differences between the tensile properties of thick-walled and thin-walled fibers. Also viscose fibers showed considerable variation and nonhomogeneity based on their stress strain-behavior and number of $\mathrm{HCl}$ induced fiber cleavages.

Comparison of the tensile tests of individual fibers and paper suggest that only a part of the elongation potential of individual fibers can be utilized in the elongation of paper and the fiber bonding governs not only the strength but also the elongation of fiber networks. Elongation of paper can be promoted by securing a high bonding ability of fibers and enabling shrinkage of fiber network. HC refining increased kinks and decreased the shape factor of the pulps and therefore had a major influence on the strength properties of the sheets, yet had only a minor influence on individual fibers. The results indicate that microcompressions and individual fiber extensibility play a smaller role in sheet extensibility than has been assumed. Unrestrained drying of BSKP fiber sheets in combination with increased fiber bond strength seemed to be a promising approach for increasing the extensibility of paper.

The key conclusion related to this investigation was that the increased network elongation was created by two factors. First, increased bonding improved paper strength and thus increased the strain to break. Second, the role of free shrinkage was again shown to be pivotal for sheet extensibility. Single fiber extensibility was not critical and seemed not to limit the extensibility of the paper.

Acknowledgments Open access funding provided by Technical Research Centre of Finland (VTT). This work has been funded by the ExtBioNet project supported by the Academy of Finland, the ACel program of the Finnish Bioeconomy Cluster CLIC Innovation and Association of
European Fibre and Paper Research Organizations (EFPRO). Funding by the Academy of Finland, the Finnish Funding Agency for Technology and Innovation (TEKES) and the Association of European Fibre and Paper Research Organizations (EFPRO) is gratefully acknowledged. Also the financial support for the CD Laboratory from the Austrian Federal Ministry of Science, Research and Economy and the National Foundation for Research, Technology and Development is gratefully acknowledged.

Open Access This article is distributed under the terms of the Creative Commons Attribution 4.0 International License (http:// creativecommons.org/licenses/by/4.0/), which permits unrestricted use, distribution, and reproduction in any medium, provided you give appropriate credit to the original author(s) and the source, provide a link to the Creative Commons license, and indicate if changes were made.

\section{References}

Alexander SD, Marton R (1968) Effect of beating and wet pressing on fiber and sheet properties. II. Sheet properties. Tappi 51(6):283-288

Alexander SD, Marton R, McGovern SD (1968) Effect of beating and wet pressing on fiber and sheet properties. I. Individual fiber properties. Tappi 51(6):277-283

Ander P, Daniel G, Garcia-Lindgren C, Marklund A (2005) Characterization of industrial and laboratory pulp fibres using $\mathrm{HCl}$, Cellulase and FiberMaster analysis. Nord Pulp Pap Res J 20(1):115-120

Ander P, Hildén L, Daniel G (2008) Cleavage of softwood kraft pulp fibers by $\mathrm{HCl}$ and cellulases. BioResources 3(2):477-490

Bernt I (2011) Fine-tuning of paper characteristics by incorporation of viscose fibres. Lenzing Ber 89:78-85

Bledzki AK, Gassan J (1999) Composites reinforced with cellulose based fibres. Prog Polym Sci 24(2):221-274. https:// doi.org/10.1016/S0079-6700(98)00018-5

Borodulina S, Kulachenko A, Tjahjanto DD (2015) Constitutive modeling of a paper fiber in cyclic loading applications. CompUT Mater Sci 110:227-240. https://doi.org/10.1016/ j.commatsci.2015.08.039

Dong F, Olsson A-M, Salmén L (2010) Fibre morphological effects on mechano-sorptive creep. Wood Sci Technol 44:475-483. https://doi.org/10.1007/s00226-009-0300-3

Dumbleton DP (1971) Longitudinal compression of individual fibers. Doctoral Thesis, The Institute of Paper Chemistry, Appleton, Wisconsin

Duncker B, Nordman L (1965) Determination of the strength of single fibres. Paperi Puu 47(10):539-552

Ebeling KI (1976) Distribution of energy consumption during the straining of paper. In: The fundamental properties of paper related to its uses, Trans. Vth Fund. Res. Symp. Cambridge, pp 305-335

Fischer WJ, Hirn U, Bauer W, Schennach R (2012) Testing of individual fiber-fiber joints under biaxial load and simultaneous analysis of deformation. Nord Pulp Pap Res J 27(2):237-244 
Gierlinger N, Wimmer R (2004) Radial distribution of heartwood extractives and lignin in mature European Larch. Wood Fiber Sci 36(3):387-394

Groom L, Mott L, Shaler S (2002) Mechanical properties of individual Southern pine fibers. Part I. Determination and variability of stress-strain curves with respect to tree height and juvenility. Wood Fiber Sci 34(1):14-27

Hamad W, Gurnagul N, Gulati D (2012) Analysis of fibre deformation processes in high-consistency refining based on Raman microscopy and X-ray diffraction. Holzforschung 66:711-716

Hardacker KW (1970) Effects of loading rate, span and beating on individual wood fiber tensile properties. In: Page DH (ed) The physics and chemistry of wood pulp fibers. Tappi Stap 8:201-216

Hardacker KW, Brezinski JP (1973) The individual fiber properties of commercial pulps. Tappi 56(4):154-157

Hill RL (1967) The creep behavior of individual pulp fibers under tensile stress. Tappi 56(8):432-440

Hornatowska J (2009) Fracture mechanisms observed during tensile testing of single fibres. Workshop on Single Fiber Testing and Modeling, Innventia AB, Stockholm, Sweden, 4-5 November, 2009, pp. 17

Hubbe MA (2014) Prospects for maintaining strength of paper and paperboard products while using less forest resources: a review. BioResources 9(1):1634-1763

Ilvessalo-Pläffli MS (1995) Fiber atlas: identification of papermaking fibers. Springer, Berlin, pp 33-163

Jajcinovic M, Fischer WJ, Hirn U, Bauer W (2016) Strength of individual hardwood fibres and fibre to fibre joints. Cellulose 23:2049-2060

Janes RL (1992) Fiber characteristics. Tappi Notes

Jayme BA (1959) Mechanische Eigenschaften von Holzfasern. Tappi 42(6):461-467

Jentzen CA (1964) The effect of stress applied during drying on some of the properties of individual pulp fibers. Tappi 47(7):412-418

Kallmes OJ, Perez M (1965a) Load/elongation properties of fibres. In: Consolidation of the paper web, Trans. IIIrd Fund. Res. Symp. Cambridge, pp 507-528

Kallmes OJ, Perez M (1965b) A new theory for the load/elongation properties of paper. In: Consolidation of the paper web, Trans. IIIrd Fund. Res. Symp. Cambridge, pp 779-800

Kappel L, Hirn U, Bauer W, Schennach R (2009) A novel method for the determination of bonded area of individual fiber-fiber bonds. Nord Pulp Pap Res J 24(2):199-205

Ketola A, Strand A, Sundberg A, Kouko J, Oksanen A, Salminen K, Fu S, Retulainen E (2018) Effect of micro and nanofibrillated cellulose on the drying shrinkage, extensibility, and strength of fibre networks. BioResources 13(3):5319-5342

Keunecke D, Eder M, Burgert I, Niemtz P (2008) Micromechanical properties of common yew (Taxus baccata) and Norway spruce (Picea abies) transition wood fibers subjected to longitudinal tension. J Wood Sci 54(5):420-422

Khakalo A, Vishtal A, Retulainen E, Filpponen I, Rojas OJ (2017a) Mechanically-induced dimensional extensibility of fibers towards tough fiber networks. Cellulose 24:191-205. https://doi.org/10.1007/s10570-016-1102-z
Khakalo A, Kouko J, Filpponen I, Retulainen E, Rojas O (2017b) In-plane compression and biopolymer permeation enable superstretchable fiber webs for thermoforming toward 3-D structures. ACS Sustain Chem Eng 5(10):9114-9125. https://doi.org/10.1021/acssuschemeng. $7 \mathrm{~b} 02025$

Kouko J, Retulainen E (2018) The relationship between shrinkage and elongation of bleached softwood kraft pulp sheets. Nord Pulp Pap Res J. https://doi.org/10.1515/npprj2018-3057

Kouko J, Setälä H, Tanaka A, Khakalo A, Ropponen J, Retulainen E (2018) The effect of oxyalkylation and application of polymer dispersions on the thermoformability and extensibility of paper. Carbohydr Polym 186:411-419. https://doi.org/10.1016/j.carbpol.2018.01.071

Leopold B (1966) Effect of pulp processing on individual fiber strength. Tappi 49(7):315-318

Leopold B, McIntosh DC (1961) Chemical composition and physical properties of wood fibres. Tensile strength of individual fibers from alkali extracted loblolly pine holocellulose. Tappi 44(3):235-240

Lichtenegger H, Reiterer A, Stanzl-Tschegg SE, Fratzl P (1999) Variation of cellulose microfibril angles in softwoods and hardwoods: a possible strategy of mechanical optimization. J Struct Biol 128:257-269

Lindström T, Wågberg L, Larsson T (2005) On the nature of joint strength in paper-a review of dry and wet strength resins used in paper. In: I'Anson SJ (ed) Advances in paper science and technology, Trans. XIIIth Fund. Res. Symp. Oxford, pp 457-562

Long JM, Batchelor WJ (2018) Influence of tensile straining and fibril angle on the stiffness and strength of previously dried kraft pulp fibers. Tappi J 17(7):383-392

Lorbach C, Fischer WJ, Gregorova A, Hirn U, Bauer W (2014) Pulp fiber bending stiffness in wet and dry state measured from moment of inertia and modulus of elasticity. BioResources 9(3):5511-5528

Lundahl MJ, Cunha AG, Rojo E, Papageorgiou AC, Rautkari L, Arboleda JC, Rojas OJ (2016) Strength and water interactions of cellulose I filaments wet-spun from cellulose nanofibril hydrogels. Sci Rep 6:30695. https://doi.org/10. 1038/srep30695

Lundqvist S-O (2002) Efficient wood and fiber characterization: a key factor in research and operation. Ann For Sci 59:491-501. https://doi.org/10.1051/forest:2002033

Luostarinen K (2012) Tracheid wall thickness and lumen diameter in different axial and radial locations in cultivated Larix sibirica trunks. Silva Fenn 46(5):707-716

Mäkelä P (2009) Effect of drying conditions on the tensile properties of paper. In: I'Anson SJ (ed) Trans. XIVth Fund. Res. Symp. Oxford, 2009, pp 1079-1094

McIntosh DC, Uhrig LO (1968) Effect of refining on loadelongation characteristics of Loblolly pine holocellulose and unbleached kraft fibers. Tappi 51(6):268-273

Mohlin U-B, Dahlbom J, Hornatowska J (1996) Fiber deformation and sheet strength. Tappi 79(6):105-111

Mott L, Shaler SM, Groom LH, Liang BH (1995) The tensile testing of individual wood fibres using ESEM and video image analysis. Tappi 78(5):143-148

Mott L, Groom L, Shaler S (2002) Mechanical properties of individual Southern pine fibers. Part II. Comparison of 
earlywood and latewood fibers with respect to tree height and juvenility. Wood Fiber Sci 34(2):221-237

Olsson A-M, Salmén L (2014) Mechano-sorptive creep in pulp fibres and paper. Wood Sci Technol 48(3):569-580. https:// doi.org/10.1007/s00226-014-0624-5

Paavilainen L (1993) Influence of fibermorphology and processing on the softwood sulphate pulp fibre and paper properties. Helsinki University of Technology, Espoo

Page DH, El-Hosseiny F (1983) The mechanical properties of single wood pulp fibres. Part VI. Fibril angle and the shape of the stress-strain curve. J Pulp Pap Sci 9(4):99-100

Page DH, Seth RS (1980) The elastic modulus of paper III: the effects of dislocation, microcompressions, curls, crimps and kinks. Tappi 63(10):99-102

Page DH, El-Hosseiny F, Winkler K, Bain R (1972) The mechanical properties of single wood pulp fibres. I. A new approach. Pulp Paper Mag Can 73(8):T198-T203

Page DH, El-Hosseiny F, Winkler K, Lancaster APS (1977) Elastic modulus of single wood pulp fibers. Tappi 60(4):114-117

Page DH, Seth RS, Jordan BD, Barbe MC (1985) Curls, crimps, kinks and microcompressions in pulp fibres: their origin, measurement and significance. In: Punton V (ed.) Papermaking raw materials, Trans. VIIIth Fund. Res. Symp. Oxford, pp 183-227

Schniewind AP (1966) On differences in the tensile strength of earlywood and latewood tracheids. Holz Roh Werkst 24(10):502-506
Seth RS (2005) Understanding sheet extensibility. Pulp Paper Mag Can 106(2):33-40

Spiegelberg HL (1966) The effect of hemicelluloses on the mechanical properties of individual pulp fibers. Tappi 49(9):388-396

Van den Akker JA, Jentzen CA, Spiegelberg HL (1965) Effects on individual fibres of drying under tension. In: Consolidation of the paper web, Trans. IIIrd Fund. Res. Symp. Cambridge, pp 477-506

Vishtal A, Retulainen E (2014) Boosting the extensibility potential of fiber networks: a review. BioResources 9(4):7951-8001

Wang G, Shi SG, Wang J, Yu Y, Cao S, Cheng H (2011) Tensile properties of four types of individual cellulosic fibers. Wood Fiber Sci 43(4):353-364

West WB (1964) High consistency refining of papers. Tappi 47(6):313-317

Yiannos PN (1964) The apparent cell-wall density of wood and pulp fibers. Tappi 47(8):468-471

Zeng X, Retulainen E, Heinemann S, Fu S (2012) Fibre deformations induced by different mechanical treatments and their effect on zero-span strength. Nord Pulp Pap Res J 27(2):335-342

Zeng X, Vishtal A, Retulainen E, Sivonen E, Fu S (2013) The elongation potential of paper how should fibres be deformed to make paper extensible? BioResources 8(1):472-486 